\title{
Distrito
}

\section{Agropecuário de Manaus}

Palavras de encerramento à Reuniăo sobre TECNOLO. GIA DE DESMATAMENTO, realizada em Manaus no período de 30 de agosto a 03 de setembro de 1976.
Antes de comentar propriamente a reunião, gostariamos de reavivar aqui as diretrizes adotadas e as preocupaçōes da SUFRAMA com relação ao Distrito Agropecuário. Nós gostamos muito do pronunciamento do estudante de ecologia do INPA porque o que ele disse nos toca de perto, uma vez que é impossíve! deixar de ter cada vez mais presente a extrema responsabilidade que estamos assumindo com este projeto. Quando a SUFRAMA resolveu executar o projeto, tivemos muitas dúvidas. Mas o fato é que, ao longo da convivência com a implantação do Distrito Agropecuário, viemos amadurecendo nossa opinião a respeito do assunto.

O Distrito Agropecuário visa tornar uma área - hoje improdutiva - produtiva. Com isto pretende criar benefícios para os habitantes de Manaus tanto com relação ao consumo da produção quanto à geração de empregos. Este é o objetivo básico do projeto, decorrente do crescimento urbano de Manaus e de seus problemas. O objetivo produtivo do Distrito, que é o principal, não deve, todavia, a nosso ver, ser perseguido de forma a que cause malefícios muito maiores. E estes, em termos de Amazônia, são os relativos à predação dos recursos na. turais. Quando a SUFRAMA resolveu implantar o Distrito Agropecuário da forma como o está fazendo, pensamos muito sobre qual seria a alternativa. Se nós não concebermos um projeto para ser controlado, dentro do qual a pesquisa esteja envolvida por todos os meios possiveis - insisto - qual é a alternativa? Francamente, e para ser realista, a alternativa é a continuação do desmatamento esparso, cada empresário tomando sua própria iniciativa. Nós não conseguimos ver no país nenhuma tendência a se "fechar a Amazônia para balanço", enquanto a pesquisa obtém as respostas.

Então, se não existe esta tendência, e se estamos assistindo a desmatamentos em toda a Amazônia por iniciativa isolada de empresários que não se preocupam em procurar a pesquisa, pensamos que o Distrito é uma alternativa realista de procurar tornar estes solos produtivos de forma controlada. A Amazônia tem 270 milhões de hectares. O Distrito Agropecuário tem 600.000 ha., aproximadamente, sendo que $20 \%$ serão utilizados em 10 anos. Porisso, apelamos aos pesquisadores e aos órgãos de pesquisa aqui presentes para que exercitem toda a sua criatividade para propor à SUFRAMA os mecanismos de controle, como também mecanismos de observação, para permitir que retiremos deste Distrito dados científicos de tal monta que o Governo tenha no futuro elementos para definir sua política quanto à regiăo toda, neste particular da preservação dos recursos. Um dos principais motivos pelos quais o Governo ainda não tomou uma posição explícita com relação ao desmatamento na Amazônia, além do que está no Código Florestal, considerado permissivo em certos círculos, é a falta de dados que suportem cientificamente tal tomada de posição. Propomos que 
persigamos, pesquisa, extensão rural, empresários, todos os interessados, enfim, um modelo que torne o Distrito produtivo e ao mesmo tempo um laboratório científico capaz de gerar respostas para toda a Amazônia, porque não há dúvida de que os solos do Distrito Agropecuário são representativos da maior parte da região. Então, vamos tornar o Distrito um laboratório capaz de gerar respostas não só quanto ao que produzir economicamente mas também quanto ao como produzir sem predar a Amazônia. Queremos que a pesquisa entre no Distrito Agrope cuário e realize aí as atividades necessárias para que no mais curto espaço de tempo possível possamos ter respostas sólidas sobre os efeitos de ocupar a Amazônia com agricultura.

Em síntese, o que a SUFRAMA está oferecendo à pesquisa é uma oportunidade que esta não teve até agora, face à forma desordenade da ocupação posta em prática. E acreditamos que, se concentrarmos esforços e recursos $\epsilon$ pensarmos em projetos objetivos de pesquisa, ao longo de 5 a 10 anos poderemos ter uma massa de dados tão grande que qualquer Governo pensará muito antes de refutá-los ou de não usá-los em suas definições de política para a região. Este é o sentido exato que nós queremos colocar em relação à posição do Distrito Agropecuário e aos recursos naturais da Amazônia. A SUFRAMA já tem tido algumas iniciativas no sentido de articular-se com a pesquisa, de comprar projetos de pesquisa e de facilitar a instalação de órçãos de pesquisa dentro do Distrito. No entanto, nós pedimos aos pesquisadores que tomem a iniciativa de apresentar à SUFRAMA os projetos que eles considerem básicos para que no futuro a pesquisa possa se pronunciar cabalmente sobre o problema. A SUFRAMA não tem capacidade técnica para identificar estes projetos em sua totalidade. Então, os pesquisadores não podem adotar uma atitude de espera a que a SUFRAMA os solicite a apresentar projetos. Esta solicitação já está feita agora. Nós pediriamos que se somasse toda a criatividade e todos os conhecimentos para que estes projetos fossem apresentados à SUFRAMA. E a pesquisa deve provocar a SUFRAMA para que estes projetos sejam efetivamente implantados no Distrito Agropecuário. Não temos dúvida de que os investimentos da SUFRAMA em pesquisa aumentarão nos próximos anos, se houverem bons projetos. Nossos recursos são reduzidos mas queremos gerar este exemplo.

Um programa deste tipo trará benefícios para a conservação do patrimônio do país e para os próprios empresários que corajosamente estão Implantando suas empresas no Distrito.

Embora nós creiamos que os empresários certamente darão todo o apoio para que a pesquisa use suas propriedades para fazer os experimentos e observações, já que eles serão beneficiários desta ação, a SUFRAMA procurará influenciá-los para que colaborem neste sentido.

Com relação à reunião em si, deve ser considerada apenas um passo no esforço global que estamos fazendo com este projeto. Um passo muito importante. Mas é evidente que as respostas obtidas nos trabalhos de grupo não conseguiram atender a todas as interrogantes colocadas. Assim, a única possibilidade que vemos de se promover 
uma reunião útil no próximo ano, é fazermos algo de observação e de intervenção organizada e científica na área para que tenhamos alguns dados novos.

Nesta linha, queremos fazer novas reuniões. Achamos que os empresários do Distrito Agropecuário esião começando sues atividades som uma vantagem muito grande em relação a outros empresários da Amazônia. Muitas coisas interessantes foram ditas e embora carecendo, em alguns casos, de comprovação de resultados, servem para acautelamento em relação ao que será feito. Para a questão do tamanho dos desmatamentos contínuos, por exemplo, nós pediríamos toda a atenção do empresariado. Tivemos aqui dois depoimentos muito segures sobre experiências mal sucedidas com desmatamentos de grande extensão. Este parece estar na exata medida da capacidade da empresa de cobrir o solo rapidamente com o cultivo substituto da floresta.

As empresas do Distrito Agropecuário são pequenas (em relação à média das já implantadas ou em implantação na Amazônia) e achamos que os desmatamentos devem ser feitos em áreas contínues de tamanho reduzido.

Vimos o exemplo de queimada de 1.000 hectares que gerou chuva que veio a apagá-la e tornou a prática anti-econômica. Vimos tam. bém, com muito prazer, a exposição do diretor da COLOAMA, enpresa sediada no Acre. quando ele mostrou que estão aplicando um sistema tipo "tabuleíro de xadrez" onde a mata é derrubada em talhões de 25 hectares, alternados com talhões do mesmo tamanho, onde a fioresta permanece. Açui se propôs manejo, no casò de pastagens, como uma forma de diminuir problemas com o capim e a preservação do solo. No entanto, para que o manejo seja bem feito, é preciso que a área desmatada seja reduzida, a meu ver.

É mais fácil manejar áreas reduzıdas, e se desmatamentos extensos forem feitos, estaremos introduzindo problemas de manejo.

Chamamos, portanto, a atenção dos empresários do Distrito para que observem estas sugestões no sentidc de desmatar pequenas áreas intercaladas com florestas, o que tornará as áreas mais manejáveis.

Houve diversos outros tipos de sugestões como a da formação de uma cooperativa dos produtores do Distrito Agropecuário que nos agrada muito. Nossas experiências em cooperativismo no Amázonas têm sido negativas. Mas, infelizmente, produtores pobres só podem formar cooperativas pobres e se não houver um apoio substancial do Governo, cooperativas deste tipo nẽo podem prosperar. No caso do Distrito, a cooperativa seria relativamente forte, pois, formada de empresários. A SUFRAMA examinará a viabilidade desta proposta.

Procuraremos fazer um esforço para publicar os resultados desta reunião. A SUFRAMA, a EMBRAPA e a SEPROR poderão fazer comentários à parte mas transcreveremos na integra a maior parte dos debates e os resultados dos trabalhos de grupo.

Por outro lado, nunca é demais insistir em qua a SUFRAMA tem recursos muito reduzidos para executar isoladamente este projeto e 
me refiro, mais especificamente, aos recursos humanos. Cada vez que o Distrito é discutido surgem novas idéias e facetas, caracterizando a existência de um projeto complexo. Este é um projeto para ser executado não só pela SUFRAMA mas por todo o setor público agrícola do Amazonas. A SUFRAMA reafirma aqui sua posição favorável à integração institucional, reforçando o convite para que todas as instituições ligadas ao problema, cada uma dentro de suas funções, participem da implantação do Distrito Agropecuário.

Agradeço a participação de todos. Esta reunião serviu, inclusive, para reavivar nossa crença na capacidade de colaboração mútua entre as pessoas e as instituiçōes. Fica provado, mais uma vez, que um projeto complexo, não pode ser implantado por apenas um setor de interesse. Ao contrário, exige uma abordagem multidisciplinar, multinstitucional, a atuação combinada de diversos setores de interesses para que todos os fatores relevantes sejam considerados.

Ao encerrar a reuniăo, eu os convido a seguir conosco e dar no. vos passos para a implantação do Distrito Agropecuário de Manaus.

Marcilio Reis de Avelar Junqueira

Eng. Agrônomo 